\title{
Reduced Physical Activity With Bronchiectasis
}

\author{
Anderson José PT PhD, Tamires Machado Ramos PT, Rejane Agnelo Silva de Castro PT MSc, \\ Cristiane Santos de Oliveira PT, Anderson Alves de Camargo PT PhD, \\ Rodrigo Abensur Athanazio MD PhD, Samia Zahi Rached MD MSc, Rafael Stelmach MD PhD, \\ and Simone Dal Corso PT PhD
}

\begin{abstract}
BACKGROUND: Bronchiectasis leads to reduced functional capacity, which might have implications for physical activity. The impact of dyspnea and long-term oxygen therapy on physical activity has never been investigated in subjects with bronchiectasis. Based on these findings, specific strategies could be applied to allow individuals to be more active in their daily life. In this study we aimed to evaluate physical activity, the impact of dyspnea and long-term oxygen therapy on physical activity, and the determinants of physical activity in subjects with bronchiectasis. METHODS: We performed a cross-sectional study in 139 subjects with bronchiectasis (age $45 \pm 13$ y, FVC $70 \pm 22 \%$ of predicted, $\mathrm{FEV}_{1} 54 \pm 25 \%$ of predicted) and 49 healthy subjects as controls. Physical activity was assessed using steps per day (measured with a pedometer), spirometry, incremental shuttle walking test (ISWT), and dyspnea. RESULTS: Reduced physical activity was observed in subjects with bronchiectasis, who recorded a median (interquartile range) of 8,007 (5,131-10,432) steps/d compared with controls, who recorded 10,994 $(8,551-14,078)$ steps $/$ d $(P<.001)$. Significant correlations were observed between physical activity and FVC $(r=0.43), \mathrm{FEV}_{1}(r=0.36)$, ISWT $(r=0.37)$, and dyspnea $(r=-0.48)$. Determinants for reduced physical activity included pulmonary function $\left(R^{2}=0.150\right)$, dyspnea $\left(R^{2}=0.075\right)$, ISWT $\left(R^{2}=0.044\right)$, and long-term oxygen therapy $\left(R^{2}=0.038\right)$; these factors explained 32\% of the physical activity. CONCLUSION: Subjects with bronchiectasis exhibited reduced physical activity compared with healthy peers. Dyspnea has a negative impact on physical activity. Independent factors associated with physical activity included pulmonary function, dyspnea, functional capacity, and long-term oxygen therapy. These findings will guide strategies to enhance daily physical activity and to encourage subjects with bronchiectasis to be more active. Key words: physical activity; activities of daily living; bronchiectasis; dyspnea; exercise test; oxygen inhalation therapy. [Respir Care 2018;63(12):1498-1505. (C) 2018 Daedalus Enterprises]
\end{abstract}

\section{Introduction}

Bronchiectasis is a pulmonary disease characterized by abnormal and irreversible dilatation of the large-caliber

\footnotetext{
Drs José, de Camargo, and Dal Corso, as well as Mr Ramos, Ms de Castro, and Ms de Oliveira are affiliated with the Postgraduate Program in Rehabilitation Sciences, Universidade Nove de Julho, São Paulo, Brazil. Drs Athanazio, Rached, and Stelmach are affiliated with the Pulmonary Division, Heart Institute, Hospital das Clínicas da Faculdade de Medicina da Universidade de São Paulo, Brazil.
}

Mr Ramos and Dr de Camargo have disclosed relationships with the São Paulo Research Foundation. The other authors have disclosed no conflicts of interest. bronchi and obstruction of the walls of small and mediumsized airways by inflammatory infiltrates. ${ }^{1-3}$ Bronchiectasis is a heterogeneous disease with spirometric results that may be normal, obstructive, or restrictive. ${ }^{4}$ A cohort study showed a progressive decline in lung diffusion capacity, ${ }^{5}$ which can contribute to a limitation of pulmonary gas exchange during exertion or even at rest, resulting in the need for continuous oxygen therapy. Symptoms most com-

\footnotetext{
Correspondence: Anderson José PT PhD, Postgraduate Program in Rehabilitation Sciences, Nove de Julho University, Rua Vergueiro, 235/249, Liberdade, São Paulo, Brazil, 01504-001. E-mail: dr.andersonjose@gmail.com.
}

DOI: $10.4187 /$ respcare.05771 
monly reported by subjects with bronchiectasis are cough, dyspnea, and fatigue. To minimize or avoid dyspnea and fatigue, subjects with bronchiectasis adapt their lifestyle to their decreased functional capacity ${ }^{6}$ and reduce daily physical activity. ${ }^{7}$

Although bronchiectasis is a chronic, progressive, and debilitating disease, studies investigating the impact of bronchiectasis on physical activity are scarce. ${ }^{7,8}$ A previous study from the United Kingdom showed a high level of sedentary behavior in subjects with bronchiectasis, ${ }^{7}$ and they walk a great deal less in day-to-day life compared to Brazilian subjects with bronchiectasis, ${ }^{6}$ although the latter subjects had worse pulmonary function and functional capacity. This difference in the amount of daily physical activity among countries has been shown not only in healthy subjects but also in subjects with COPD. ${ }^{9}$ In addition to the implications of ethnicity, educational level, and socioeconomic status in determining physical activity in daily life, ${ }^{10}$ the use of long-term oxygen therapy should also be taken into account. In subjects with COPD, long-term oxygen therapy was associated with a lower level of domestic activity compared to those who did not use it. ${ }^{11}$ Due to the impairment of pulmonary gas exchange, some patients with bronchiectasis make use of long-term oxygen therapy, which can affect daily physical activity.

Although it is known that patients with bronchiectasis present with physical activity below the recommended level, ${ }^{7}$ the magnitude of this reduction is still unknown because it has never been compared to that of healthy peers. Moreover, it remains unclear whether the degree of dyspnea and long-term oxygen therapy have an impact on the level of physical activity and the determinants of physical activity in this population. Given these gaps in the literature, this study aimed to answer the following questions (1) Do subjects with bronchiectasis present reduced physical activity compared with their healthy peers? (2) Does dyspnea have an impact on physical activity? (3) Is there any correlation between physical activity and pulmonary function, functional status, and dyspnea? (4) Does daily physical activity differ among subjects who use and those who do not use long-term oxygen therapy? (5) What are the determinants of physical activity in this population? The answers to these questions will guide strategies to enhance daily physical activity in patients with bronchiectasis, not only in the out-patient environment but also where the patients live, work, and spend most of the time of their day.

\section{Methods}

\section{Sample}

This cross-sectional study assessed 139 subjects from a convenience sample. Inclusion criteria were clinical or to-

\section{QUICK LOOK}

\section{Current knowledge}

Sedentary behavior in subjects with bronchiectasis was only compared to the recommended guidelines for physical activity. However, the magnitude of reduced physical activity in this population has never been compared with their healthy peers and it is still unclear whether the degree of dyspnea and use of long-term oxygen therapy has an impact on physical activity.

\section{What this paper contributes to our knowledge}

Subjects with bronchiectasis present reduced physical activity. The better the pulmonary function and functional capacity and the lower the dyspnea, the more active the subjects are. Independent factors associated with reduced physical activity are pulmonary function, dyspnea, functional capacity, and long-term oxygen therapy. People with bronchiectasis should be encouraged to change their lifestyle and increase their physical activity level.

mographic diagnosis of bronchiectasis, ${ }^{12}$ age $\geq 18 \mathrm{y}$, and clinically stable (ie, an absence of alteration in dyspnea symptoms, amount and color of secretion, and medication during the past 4 weeks). Exclusion criteria were as follows: smokers; individuals with bronchiectasis associated with other pulmonary diseases (eg, asthma, COPD, cystic fibrosis, pulmonary fibrosis, or others), cardiovascular diseases, and hospital admissions or previous infections in the past 4 weeks; individuals who perform 30 min of physical activity $>3$ times a week (eg, playing soccer, running, swimming, cycling, weightlifting, or other sports activities), who have participated in pulmonary rehabilitation programs within the previous year, or who were unable to perform the tests due to musculoskeletal or cognitive impairment.

Study participants were recruited at the Obstructive Disease Out-patient Clinic of the University of Sao Paulo, Brazil, and were sent on to the Cardiopulmonary Rehabilitation Center of the Universidade Nove de Julho. The control group recruited in the community consisted of 49 healthy, sedentary subjects (convenience sample), and subjects were paired according to age, gender, and body mass index.

This study was approved by the Human Research Ethics Committees of the Universidade Nove de Julho (Protocol 451538) and University of Sao Paulo (Protocol 0921/11). All participants signed an informed consent form prior to study commencement. 


\section{Physical Activity in Bronchiectasis}

\section{Design}

This cross-sectional study was conducted during 2 visits: in the first visit, the participants underwent spirometry and the incremental shuttle walking test (ISWT), responded to the Medical Research Council (MRC) dyspnea questionnaire, and received pedometers (Yamax Power Walker, model PW-610, Tokyo, Japan). In the second visit, 7 days later, the participants returned the pedometers for analysis.

\section{Spirometry}

Spirometry was performed using the ULTIMA CPX (Medical Graphics, St Paul, Minnesota) metabolic stress test. The test followed the technical procedures recommended by Brazilian guidelines, ${ }^{13}$ and the values were compared with those predicted for the Brazilian population. ${ }^{14}$

\section{Incremental Shuttle Walk Test}

The ISWT was performed according to the original description ${ }^{15}$ in a hallway $10 \mathrm{~m}$ long that was marked using 2 cones placed $0.5 \mathrm{~m}$ away from each end. The participants were asked to follow this route in a predetermined manner, which was related to an audible pre-recorded rhythm. Heart rate (Polar Precision Performance; Polar Electro, Kem-skin, Finland) and oxygen pulse saturation (9500; Nonin, Plymouth, Minnesota) were continuously measured. Blood pressure, the Borg scale for dyspnea, and lower limb fatigue ${ }^{16}$ were obtained at rest and immediately after the exercise. The distance traveled was expressed in absolute values and as a percentage of the predicted value (\% pred). ${ }^{17}$ Two tests were conducted, with a resting period of 30 min between tests; the better of the 2 tests was considered for analysis.

\section{Dyspnea}

Dyspnea was assessed using the MRC dyspnea scale. ${ }^{18}$ This scale evaluates dyspnea in different activities, classifying it in 1 of 5 levels ranging from 1 to 5 ; the higher the level, the greater the impact of dyspnea on activities of daily living.

\section{Assessment of Physical Activity}

Physical activity was assessed using a Yamax pedometer. This device has consistent accuracy under both controlled and home conditions. ${ }^{19}$ After receiving the pedometer, the participants were instructed to attach it to the front right pocket of their pants for 7 consecutive days and then return the device to the laboratory. The first and last days were discarded, meaning that 3 consecutive weekdays plus the 2 days of the weekend remained for analysis. ${ }^{20}$ The participants were instructed to maintain their regular physical activity on the days they were wearing the device. They were asked to attach the pedometer in the morning, use it throughout the day, and remove it only before sleeping and prior to water-based activities. The pedometer measured the total number of steps and quick steps, with the latter accounting for a level higher than 100 steps/min, which is equivalent to moderate-to-vigorous intensity exercise. The participants were classified as follows: sedentary, $<5,000$ steps/d; low active, 5,000-7,499 steps/d; somewhat active 7,500-9,999 steps/d; active, 10,00012,499 steps/d; and highly active, $>12,500$ steps/d. ${ }^{21}$

The following variables were used for analysis:

- Total number of steps per day: mean total number of steps taken over all days evaluated ( $5 \mathrm{~d}$ : 3 weekdays and the 2 days of the weekend)

- Total number of quick steps per day: mean total number of quick steps taken over all days evaluated (5 d: 3 weekdays and the 2 days of the weekend)

- Total number of steps during weekdays: mean total number of steps taken on weekdays

- Total number of quick steps during weekdays: mean total number of quick steps taken on weekdays

- Total number of steps during the weekend: mean total number of steps taken over the 2 days of the weekend

- Total number of quick steps during the weekend: mean total number of quick steps taken over the 2 days of the weekend

\section{Statistical Analysis}

All statistical analyses were conducted using Statistical Package for the Social Sciences software (IBM SPSS, Chicago, Illinois). Normality of the data were tested with the Shapiro-Wilk test; parametric data were expressed as mean $\pm \mathrm{SD}$, and nonparametric data were expressed as mean and interquartile range. The frequency of the category variables was compared by the chi-squared test or the Fisher exact test. With regard to the parametric variables, comparisons between subjects with bronchiectasis and control individuals, and between subjects receiving long-term oxygen therapy and those who were not dependent on oxygen therapy, were made using the Student $t$ test for the independent variables and the Mann-Whitney test for the non-parametric variables. In the study group (ie, subjects with bronchiectasis), variables were compared between the different degrees of dyspnea via 1-way analysis of variance, applying the Bonferroni post hoc test for parametric data and via Kruskal-Wallis analysis with a pairwise post hoc test for nonparametric data (number of steps). 
Table 1. Subjects' Characteristics

\begin{tabular}{|c|c|c|c|}
\hline Variables & Bronchiectasis & Controls & $P$ \\
\hline Age, y & $45 \pm 1$ & $41 \pm 1$ & .069 \\
\hline Body mass index, $\mathrm{kg} / \mathrm{m}^{2}$ & $25 \pm 6$ & $25 \pm 4$ & .63 \\
\hline FVC, L & $2.4 \pm 0.9$ & $3.8 \pm 1.0$ & $<.001$ \\
\hline FVC, $\%$ predicted & $70 \pm 22$ & $100 \pm 10$ & $<.001$ \\
\hline $\mathrm{FEV}_{1}, \mathrm{~L}$ & $1.5 \pm 0.8$ & $3.2 \pm 0.8$ & $<.001$ \\
\hline $\mathrm{FEV}_{1}, \%$ predicted & $54 \pm 25$ & $101 \pm 11$ & $<.001$ \\
\hline $\mathrm{FEV}_{1} / \mathrm{FVC}$ & $63 \pm 15$ & $85 \pm 5$ & $<.001$ \\
\hline ISWT distance, $\mathrm{m}$ & $455 \pm 152$ & $681 \pm 209$ & $<.001$ \\
\hline ISWT, \% predicted & $54 \pm 16$ & $75 \pm 15$ & $<.001$ \\
\hline MRC dyspnea, median (IQR) & $3(2-4)$ & $1(1-1)$ & $<.001$ \\
\hline Median steps/d, no. (IQR) & $8,007(5,131-10,432)$ & $10,994(8,551-14,078)$ & $<.001$ \\
\hline$<5,000, n$ & $31(22)$ & $2(4)$ & $<.001$ \\
\hline $5,000-7,499, n$ & $34(25)$ & $6(12)$ & $<.001$ \\
\hline $7,500-9,999, n$ & $33(24)$ & $11(22)$ & $<.001$ \\
\hline $10,000-12,499, n$ & $16(11)$ & $14(29)$ & .79 \\
\hline$>12,500, n$ & $25(18)$ & $16(33)$ & $<.001$ \\
\hline
\end{tabular}

Moreover, differences between means and their 95\% CI are reported for parametric data, and median differences and their 95\% CI were estimated with the Hodges-Lehmann method. Correlations between physical activity and pulmonary function, functional capacity, and dyspnea were analyzed using either Pearson or Spearman's correlation according to parametric and nonparametric distribution, respectively. The effect size was calculated using Cohen's test. A posteriori, the statistical power of the sample size was calculated using $G^{*}$ Power software (Universität Dusseldorf, Germany).

Hierarchical multiple regression analysis was used to investigate the determinants of physical activity. The first model (block 1) of hierarchical regression included the following factors: age, body mass index, and gender; the second model (block 2 ) included FVC (\% pred), and FEV (\% pred); the third model (block 3 ) included the MRC dyspnea scale; the fourth model (block 4) included distance walked in the ISWT; and the fifth model (block 5) included long-term oxygen therapy. A 5\% level of significance was adopted for all statistical analyses $(P<.05)$.

\section{Results}

The study sample consisted of 139 subjects people with bronchiectasis (88 women, 63\%) and 49 healthy control individuals ( 31 women, 63\%). In consideration of the number of steps taken, the statistical power of the sample size was $>0.99$ for all variables investigated. Of the study group, 22 (19\%) subjects received long-term oxygen therapy. As expected, subjects with bronchiectasis presented with reduced pulmonary function and exercise capacity as well as greater dyspnea compared with the control group. Pulmonary function showed that $122(87.8 \%)$ subjects were obstructive, $9(6.5 \%)$ were restrictive, and $8(5.8 \%)$ showed normal values. In the obstructive subjects, 68 (48.9\%) subjects had mild obstruction, 43 (30.9\%) had moderate obstruction, and $11(7.9 \%)$ had severe obstruction. Characteristics of the sample are shown in Table 1. Participants with bronchiectasis took a lower number of steps than individuals in the control group in all conditions studied (Table 1, Fig. 1).

The classification of subjects according to the level of physical activity was as follows: $31(22 \%)$ subjects were sedentary, $34(25 \%)$ were low active, 33 (24\%) were somewhat active, $16(11 \%)$ were active, and $25(18 \%)$ were highly active. In the control subjects, 2 (4\%) subjects were sedentary, $6(12 \%)$ were low active, 11 (22\%) were somewhat active, 14 (29\%) were active, and 16 (33\%) were highly active.

Characterized according to the MRC scale, the higher the degree of dyspnea, the worse the pulmonary function, exercise capacity, and physical activity (Table 2). A positive correlation was found between the total number of steps and pulmonary function, and a moderate correlation was observed between the percentage of the distance predicted in the ISWT and dyspnea (Table 3). Subjects receiving long-term oxygen therapy $(n=117)$ showed worse physical activity, pulmonary function, degree of dyspnea and distance traveled in the ISWT compared to those who were not dependent on oxygen therapy $(n=22)$ (Table 4$)$. 


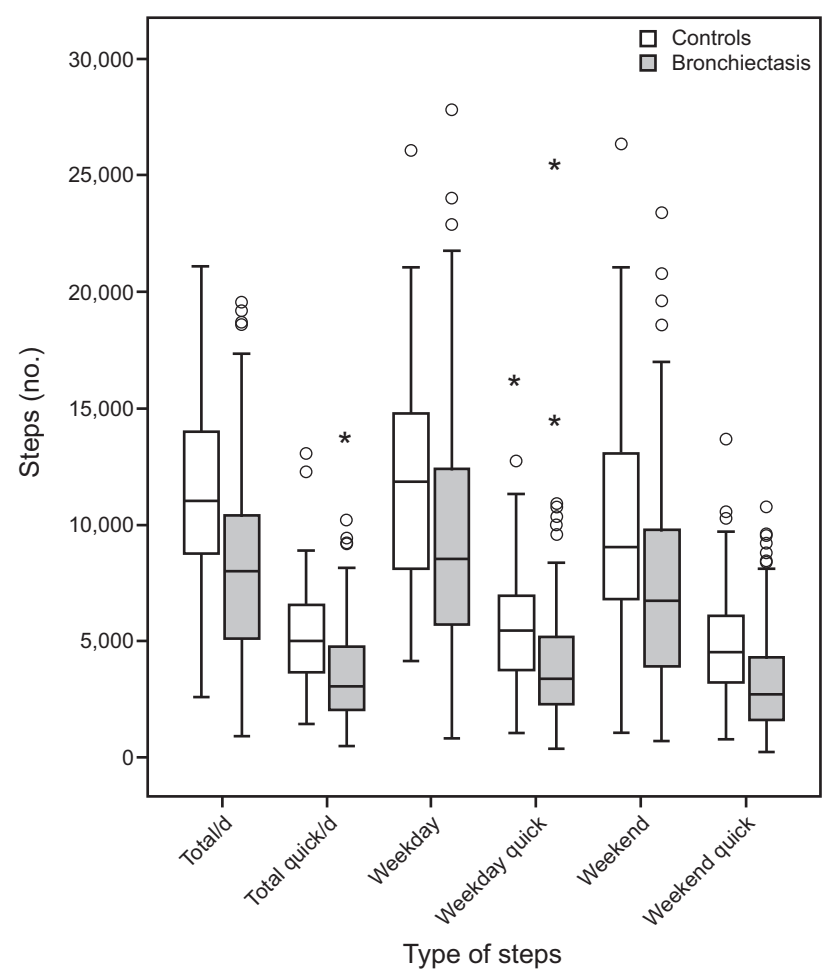

Fig. 1. Physical activity in subjects with bronchiectasis and controls. Data presented as mean $(95 \% \mathrm{Cl}) . P<.001$ between subjects with bronchiectasis and controls for all physical activity. Circles represent near outliers and asterisks indicate distant outliers.

In the hierarchical multiple regression analysis, the results of block 1 indicated that the variance $\left(\mathrm{R}^{2}\right)$ accounting for the first 3 independent variables (age, body mass index, gender) was equal to 0.052 (adjusted $\mathrm{R}^{2}=0.031$ ), which was not significantly different from zero $(P=.066)$. In block 2, 2 further independent variables $\left(\mathrm{FVC}\right.$ and $\mathrm{FEV}_{1}$, both in percent of predicted) were entered into the regression equation. The change in variance $\left(\Delta \mathrm{R}^{2}\right)$ accounted for was 0.150 , which was significantly different from zero $(P<.001)$. In block 3 , another independent variable (MRC) was entered into the regression equation and the change in variance $\left(\Delta \mathrm{R}^{2}\right)$ accounted for was equal to 0.075 , which was significantly different from zero $(P<.001)$. In block 4 , a further independent variable (ISWT) was entered into the regression equation, and the change in variance $\left(\Delta R^{2}\right)$ accounted for was equal to 0.044 , which was significantly different from zero $(P=.004)$. In block 5 , a final independent variable (long-term oxygen therapy) was entered into the regression equation, and the change in variance $\left(\Delta R^{2}\right)$ accounted for was equal to 0.038 , which was significantly different from zero $(P=.006)$. The percentage of variability in the dependent variable that can account for all the predictors together was $32 \%$.

\section{Discussion}

Our findings can be summarized as follows: subjects with bronchiectasis exhibited reduced physical activity compared to their healthy peers; dyspnea has a negative impact on physical activity; and the better the pulmonary function and functional capacity and the lower the dyspnea, the more active these individuals are in daily life. In addition to pulmonary function, dyspnea, and functional capacity, long-term oxygen therapy was identified as an independent factor associated with physical activity.

Although subjects with bronchiectasis can be considered, on average, physically active in this study $\left(8,290 \pm 4,306\right.$ steps/d), ${ }^{21} 45 \%$ (62 subjects) demonstrated physical activity below the minimum recommended level (7,000 steps/d). ${ }^{21}$ They also exhibited approximately $27 \%$ less physical activity compared to controls, and the activity rating of sedentary was attributed to nearly a quarter of the sample. A previous study by Bradley et $\mathrm{al}^{7}$ showed an even further reduced physical activity (ie, 6,001 steps per day) compared with the subjects of the present study, who were younger than those who participated in the study by Bradley et al $(45 \pm 13$ vs $63 \pm 10 \mathrm{y}$, respectively). We cannot disregard the fact that socioeconomic and demographic characteristics may also have contributed to the differences in the numbers of steps between Brazilian and North Irish subjects. This has already been demonstrated between Brazilian and Austrian individuals with COPD. ${ }^{9}$ Brazilian subjects walked longer distances, presented higher movement intensity, and spent less time sitting compared with their Austrian counterparts. The subjects of this study belong to a low-income population who live away from public transportation. They are therefore forced to walk more and, consequently, to be more active in their daily activities. ${ }^{9}$ However, we cannot rule out that, in giving each subject a pedometer, subjects received a stimulus to become immediately active, but they were instructed to maintain their regular physical activity on the days they were wearing the device. Caution is also necessary when comparing studies with different devices for counting steps. Although the accelerometer has higher accuracy than pedometers, a previous study showed that the pedometer used in our study is accurate under both controlled and free-living conditions. ${ }^{19}$

In this study, pulmonary function, dyspnea, and longterm oxygen therapy are explanatory variables of physical activity in daily life. It was not a surprise that pulmonary function contributes to the level of activity for subjects with bronchiectasis because impaired lung function usually involves an obstructive pattern, and reduced FVC has also been recorded. ${ }^{4}$ Then, FVC and $\mathrm{FEV}_{1}$ were added to a block in the hierarchical analysis. Impaired lung function has been associated with dyspnea, which in turn is negatively associated with exercise tolerance in subjects with 


\section{Physical Activity in Bronchiectasis}

Table 2. Anthropometric Data, Pulmonary Function, Exercise Capacity, and Number of Steps Categorized by MRC Scale of Subjects With Bronchiectasis

\begin{tabular}{|c|c|c|c|c|c|}
\hline & MRC1 & MRC2 & MRC3 & MRC4 & MRC5 \\
\hline Age, y & $36 \pm 13^{*}$ & $44 \pm 14$ & $47 \pm 12$ & $54 \pm 6$ & $47 \pm 11$ \\
\hline Body mass index, $\mathrm{kg} / \mathrm{m}^{2}$ & $22.7 \pm 4.9$ & $25.7 \pm 4.2$ & $25.2 \pm 5.9$ & $28.1 \pm 5.6$ & $24.1 \pm 5.8$ \\
\hline $\mathrm{FVC}, \mathrm{L}$ & $3.0 \pm 0.8^{*}$ & $2.8 \pm 0.6 \dagger$ & $2.5 \pm 0.9 \dagger$ & $1.7 \pm 0.7$ & $1.5 \pm 0.4$ \\
\hline FVC, $\%$ pred. & $79.1 \pm 18.4 \ddagger$ & $82.0 \pm 14.6 \ddagger$ & $71.5 \pm 20.6 \ddagger$ & $66.4 \pm 22.5$ & $43.9 \pm 14.1$ \\
\hline $\mathrm{FEV}_{1}, \mathrm{~L}$ & $21 \pm 0.8^{*}$ & $2.0 \pm 0.5^{*}$ & $1.5 \pm 0.7 \ddagger$ & $1.1 \pm 0.4$ & $0.8 \pm 0.3$ \\
\hline $\mathrm{FEV}_{1}, \%$ pred. & $63.8 \pm 24.9 \ddagger$ & $68.9 \pm 18.0 \ddagger$ & $54.7 \pm 23.8 末$ & $50.0 \pm 20.4$ & $29.9 \pm 14.4$ \\
\hline ISWT distance, $\mathrm{m}$ & $614.3 \pm 155.1^{*}$ & $513.9 \pm 118.9 \dagger$ & $439.7 \pm 107.0 \ddagger$ & $351.6 \pm 114.1$ & $318.0 \pm 102.8$ \\
\hline ISWT, \% pred. & $59.8 \pm 11.7 \ddagger$ & $61.8 \pm 15.7 \ddagger$ & $54.0 \pm 13.6 \neq$ & $51.7 \pm 12.7$ & $40.5 \pm 18.7$ \\
\hline Number of steps/d & $9,994(5,719-13,716) \ddagger$ & $10,432(8,488-13,652)^{*}$ & $8,226(6,089-9,459) \neq$ & $6,467(5,860-8,699) \ddagger$ & $2,758(2,277-6,644)$ \\
\hline Number of quick steps/d & $4,025(2,383-5,229) \ddagger$ & $4,676(3,731-6,565)^{*}$ & $2,970(2,359-4,235) \neq$ & $2,605(1,932-3,869)$ & $1,429(892-2,723)$ \\
\hline Total number of steps on weekdays & $9,191(6,767-14,182) \neq$ & $12,311(8,468-14,872)^{*}$ & $8,823(6,643-11,039) \neq$ & $7,567(5,963-8,886) \neq$ & $3,321(1,889-5,703)$ \\
\hline Total number of quick steps on weekdays & $4,253(2,601-6,605) \ddagger$ & $5,335(4,271-7,938)^{*}$ & $3,146(2,458-4,684) \neq$ & $3,139(2,135-3,907) \div$ & $1,715(681-2,849)$ \\
\hline Number of steps during weekend & $9,753(4,539-12,981) \ddagger$ & $9,028(6,948-10,882)^{*}$ & $6,456(4,390-9,484) \neq$ & $5,459(3,750-6,983)$ & $3,602(2,168-6,607)$ \\
\hline Number of quick steps during weekend & $3,582(1,894-5,673) \neq$ & $3,907(2,634-4,878)^{*}$ & $2,642(1,967-3,741) \neq$ & $2,070(1,215-3,373)$ & $1,419(1,030-2,560)$ \\
\hline \multicolumn{6}{|c|}{$\begin{array}{l}\text { Data expressed as mean } \pm \mathrm{SD} \text {, except data from pedometer (number of steps), which are expressed in median (interquartile range). } N=139 \text { subjects; } n=24 \text { in the MRC1 group; } n=27 \text { in the } \\
\text { MRC2 group; } n=52 \text { in the MRC3 group; } n=11 \text { in the MRC4 group; } n=25 \text { in the MRC5 group. } \\
* P<.05 \text { vs MRC3, MRC4, MRC5. } \\
\dagger P<.05 \text { vs MRC4 and MRC5. } \\
\ddagger P<.05 \text { vs MRC5. } \\
\text { MRC = Medical Research Council dyspnea scale } \\
\text { ISWT = incremental shuttle walk test }\end{array}$} \\
\hline
\end{tabular}

Table 3. Correlations Between Physical Activity in Daily Life and Lung Function, Functional Capacity, and Dyspnea

\begin{tabular}{lcccc}
\hline \hline & FVC & FEV $_{1}$ & Incremental Shuttle Walking Test & Dyspnea (MRC) \\
\hline Number of steps/d & 0.45 & 0.36 & 0.43 & -0.47 \\
Number of quick steps/d & 0.43 & 0.34 & 0.35 & -0.45 \\
Total number of steps on weekdays & 0.42 & 0.38 & 0.41 & -0.46 \\
Total number of quick steps on weekdays & 0.37 & 0.34 & 0.37 & -0.44 \\
Number of steps during weekend & 0.40 & 0.27 & 0.27 & -0.41 \\
Number of quick steps during weekend & 0.40 & 0.28 & & -0.39
\end{tabular}

Data expressed as percent of predicted, except dyspnea (MRC). $N=139$ subjects. $P<.05$ was considered statistically significant.

$\mathrm{MRC}=$ Medical Research Council dyspnea scale

bronchiectasis. ${ }^{22}$ In our study, dyspnea was one of the determinants of being active throughout the day. Based on a dyspnea spiral, ${ }^{23}$ patients with bronchiectasis reduce their physical activities of daily living to avoid or minimize this symptom, as observed by the gradual reduction in steps per day as the degree of dyspnea increased. In addition to dyspnea, the correlations in this study also showed that better pulmonary function and functional capacity allowed the subjects with bronchiectasis to be more active. The finding that functional performance is an independent predictor of daily physical activity in such individuals is in accordance with previous studies that had already associated the number of steps per day with functional capacity, measured by the distance walked in the ISWT. 6,7

Another determinant of physical activity was oxygen supplementation. In this study, the subjects who used longterm oxygen therapy were less active than those who did not. Long-term oxygen therapy reduces the mobility of individuals, causing as an undesirable effect a reduction in physical activity. This is particularly important for Brazilian patients with chronic lung diseases, because they may have difficulty acquiring mobile sources for the administration of oxygen, which will restrict their mobility by the need to remain close to the source of oxygen. However, subjects using long-term oxygen therapy also presented with worse pulmonary function, functional capacity, and greater dyspnea. Similar findings were previously described in oxygen-dependent people with COPD. ${ }^{24}$ Moreover, oxygen-dependent people with COPD present with greater levels of hypoxemia and hypercapnia, lower maximal expiratory pressure, worse quality of life, ${ }^{24}$ and a higher risk of exacerbation, hospitalization, and mortality. ${ }^{25,26}$ Whether long-term oxygen therapy has a negative impact on exacerbation rates and survival in patients with bronchiectasis remains unknown. 
Table 4. Comparison Between Subjects Receiving Long-Term Oxygen Therapy and Those Who Do Not Use it

\begin{tabular}{|c|c|c|c|}
\hline Variables & With $\mathrm{O}_{2}$ & Without $\mathrm{O}_{2}$ & Effect Size \\
\hline Age, y & $46 \pm 12$ & $45 \pm 13$ & 0.08 \\
\hline Body mass index, $\mathrm{kg} / \mathrm{m}^{2}$ & $23 \pm 5$ & $25 \pm 6$ & 0.36 \\
\hline FVC, L & $1.5 \pm 0.5^{*}$ & $2.6 \pm 0.9$ & 1.51 \\
\hline FVC, $\%$ predicted & $44 \pm 18^{*}$ & $74 \pm 19$ & 1.62 \\
\hline $\mathrm{FEV}_{1}, \mathrm{~L}$ & $0.8 \pm 0.3^{*}$ & $1.7 \pm 0.7$ & 1.67 \\
\hline $\mathrm{FEV}_{1}, \%$ predicted & $28 \pm 11 *$ & $59 \pm 23$ & 1.72 \\
\hline $\mathrm{FEV}_{1} / \mathrm{FCV}$ & $56 \pm 13^{*}$ & $65 \pm 14$ & 0.67 \\
\hline ISWT distance, $\mathrm{m}$ & $299 \pm 93 *$ & $484 \pm 143$ & 1.53 \\
\hline ISWT, \% predicted & $35 \pm 12 *$ & $57 \pm 14$ & 1.68 \\
\hline MRC dyspnea, median (IQR) & $5(5-5)^{*}$ & $3(2-3)$ & 2.44 \\
\hline Number of steps/d & $2,672(2,101-4,785)^{*}$ & $8,665(6,270-11,181)$ & 1.80 \\
\hline Number of quick steps/d & $1,086(829-2,018)^{*}$ & $3,543(2,546-5,041)$ & 1.58 \\
\hline Total number of steps on weekdays & $2,632(1,492-4,908) *$ & $9,056(6,873-12,778)$ & 1.83 \\
\hline Total number of quick steps on weekdays & $1,150(621-2,000)^{*}$ & $3,786(2,566-5,746)$ & 1.39 \\
\hline Number of steps during weekend & $2,968(2,030-4,227)^{*}$ & $7,685(5,028-10,507)$ & 1.34 \\
\hline Number of quick steps during weekend & $1,113(750-1,817)^{*}$ & $3,000(2,112-4,598)$ & 1.27 \\
\hline
\end{tabular}

Our findings have important implications for clinicians who deal with patients with bronchiectasis because the level of physical activity is an isolated factor of mortality and hospitalization in other chronic pulmonary disease. ${ }^{27,28}$ Assessment of daily physical activity should be incorporated in the evaluation of patients with bronchiectasis. Those patients who have already performed the recommended physical activity level should be guided to keep it. Particular strategies, such as coaching or motivational interviewing, should be given for those who present with higher levels of dyspnea and use long-term oxygen therapy.

\section{Study Limitations}

This study had some limitations. It is well known that accelerometers can provide additional and more accurate information on physical activity than pedometers, but they are costly and are not available to most rehabilitation clinics. The first and last days in the step count evaluation were disregarded, limiting the count to 3 weekdays. This was necessary because most of the subjects reside far from our pulmonary rehabilitation center; therefore, to consider the days when they commuted to receive and return the pedometers would have overestimated their physical activity on those days. Finally, the accuracy and reproducibility of pedometers are error-prone. However, the model used in this study has already been tested and presented good internal consistency and accuracy in various situations. ${ }^{19}$

\section{Conclusion}

People with bronchiectasis present with reduced physical activity compared to healthy control individuals. The degree of dyspnea has a negative impact on physical activity. The better the pulmonary function and functional capacity and the lower the dyspnea, the more active people with bronchiectasis are. Independent factors associated with reduced physical activity include pulmonary function, dyspnea, functional capacity, and long-term oxygen therapy.

\section{ACKNOWLEDGMENT}

We thank Gianni Santos for statistical support.

\section{REFERENCES}

1. Barker AF. Bronchiectasis. N Engl J Med 2002;346(18):1383-1393.

2. Cole PJ. A new look at the pathogenesis and management of persistent bronchial sepsis: a "vicious cycle" hypothesis and its logical therapeutic connotations. In Davies RJ, editor. Strategies for the management of chronic bronchial sepsis: Proceedings of a symposium held at the Charing Cross Hospital. London: Medical Education Services. 1984;12:1-20.

3. Chang $\mathrm{AB}$, Bilton D. Exacerbations in cystic fibrosis: non-cystic fibrosis bronchiectasis. Thorax 2008;63(3):269-276.

4. Drain M, Elborn SJ. Assessment and investigation of adults with bronchiectasis. Eur Respir Mon 2011;52:32-43.

5. King PT, Holdsworth SR, Freezer NJ, Villanueva E, Farmer MW, Guy P, Holmes PW. Lung diffusing capacity in adult bronchiectasis: a longitudinal study. Respir Care 2010;55(12):1686-1692.

6. de Camargo AA, Amaral TS, Rached SZ, Athanazio RA, Lanza FC, Sampaio LM, et al. Incremental shuttle walking test: a reproducible 


\section{Physical Activity in Bronchiectasis}

and valid test to evaluate exercise tolerance in adults with noncystic fibrosis bronchiectasis. Arch Phys Med Rehabil 2014;95(5):892-899.

7. Bradley JM, Wilson JJ, Hayes K, Kent L, McDonough S, Tully MA, et al. Sedentary behaviour and physical activity in bronchiectasis: a cross-sectional study. BMC Pulm Med 2015;15:61.

8. Wilson JJ, Kirk A, Hayes K, Bradbury I, McDonough S, Tully MA, et al. Applying the transtheoretical model to physical activity behavior in individuals with bronchiectasis. Respir Care 2016;61(1):68-77.

9. Pitta F, Breyer MK, Hernandes NA, Teixeira D, Sant'Anna TJP, Fontana $\mathrm{AD}$, et al. Comparison of daily physical activity between COPD patients from Central Europe and South America. Respir Med 2009;103:421-426.

10. Watz H, Pitta F, Rochester CL, Garcia-Aymerich J, ZuWallack R, Troosters T, et al. An official European Respiratory Society statement on physical activity in COPD. Eur Respir J 2014;44:15211537.

11. Sandland CJ, Singh SJ, Cursio A, Jones PM, Morgan MD. A profile of daily activity in chronic obstructive pulmonary disease. J Cardiopulm Rehabil 2005;25(3):181-183.

12. Athanazio RA, Rached SZ, Rohde C, Pinto RC, Fernandes FLA, Stelmach R. Should the bronchiectasis treatment given to cystic fibrosis patients be extrapolated to those with bronchiectasis from other causes? J Bras Pneumol 2010;36(4):425-431.

13. Sociedade Brasileira de Pneumologia e Tisiologia. Diretrizes para testes de função pulmonar. J Pneumol 2002;28(Suppl 3):iii1-iii82.

14. Pereira CAC, Sato T, Rodrigues SC. New reference values for forced spirometry in white adults in Brazil. J Bras Pneumol 2007;33(4): 397-406.

15. Singh SJ, Morgan MD, Scott S, Walters D, Hardman AE. Development of a shuttle walking test of disability in patients with chronic airways obstruction. Thorax 1992;47(12):1019-1024.

16. Borg GA. Psychophysical bases of perceived exertion. Med Sci Sports Exerc 1982;14(5):377-381.

17. Probst VS, Hernandes NA, Teixeira DC, Felcar JM, Mesquita RB, Gonçalves CG, et al. Reference values for the incremental shuttle walking test. Respir Med 2012;106(2):243-348.

18. Kovelis D, Segretti NO, Probst VS, Lareau SC, Brunetto AF, Pitta F. Validation of the Modified Pulmonary Functional Status and Dys- pnea Questionnaire and the Medical Research Council scale for use in Brazilian patients with chronic obstructive pulmonary disease. J Bras Pneumol 2008;34(12):1008-1018.

19. Le Masurier GC, Lee SM, Tudor-Locke C. Motion sensor accuracy under controlled and free-living conditions. Med Sci Sports Exerc 2004;36(5):905-910.

20. Cain KL, Sallis JF, Coway TL, Dyck DV, Calhoon L. Using accelerometers in youth physical activity studies: a review of methods. J Phys Act Health 2013;10(3):437-450.

21. Tudor-Locke C, Hatano Y, Pangrazi RP, Kang M. Revisiting "how many steps are enough?" Med Sci Sports Exerc 2008;40(Suppl 7): iii537-iii543.

22. Koulouris NG, Retsou S, Kosmas E, Dimakou K, Malagari K, Mantzikopoulos G, et al. Tidal expiratory flow limitation, dyspnoea and exercise capacity in patients with bilateral bronchiectasis. Eur Respir J 2003;21(5):743-748.

23. Préfaut C, Varray A, Vallet G. Pathophysiological basis of exercise training in patients with chronic obstructive lung disease. Eur Respir Rev 1995;5(25):27-32.

24. Ferreira CAS, Stelmach R, Feltrin MIZ, Filho WJ, Chiba T, Cukier A. Evaluation of health-related quality of life in low-income patients with COPD receiving long-term oxygen therapy. CHEST 2003; 123(1):136-141.

25. García-Rivero JL, Esquinas C, Barrecheguren M, Bonnin-Vilaplana M, García-Sidro P, Herrejón A. Risk factors of poor outcomes after admission for a COPD exacerbation: multivariate logistic predictive models. COPD 2017;14(2):164-169.

26. Carone M, Antoniu S, Baiardi P, Digilio VS, Jones PW, Bertolotti G; QuESS Group. Predictors of mortality in patients with COPD and chronic respiratory failure: the quality-of-life evaluation and survival study (QuESS): a three-year study. COPD 2016;13(2):130-138.

27. Waschki B, Kirsten A, Holz O, Müller K-C, Meyer T, Watz H, et al. Physical activity is the strongest predictor of all-cause mortality in patients with COPD: a prospective cohort study. Chest 2011;140(2): 331-342.

28. Garcia-Rio F, Rojo B, Casitas R, Lores V, Madero R, Romero D, et al. Prognostic value of the objective measurement of daily physical activity in patients with COPD. Chest 2012;142(2):338-346. 